\title{
QUITARSE EL PESO DE LA HISTORIA: ISIDORO VALCÁRCEL MEDINA Y SU 2000 D. DE J. C. ${ }^{1}$
}

\author{
Ignacio ESTELLA NORIEGA \\ Universidad Autónoma de Madrid \\ ignacio.estella@uam.es
}

2 000 d. de J. C., del artista premio Nacional de Bellas Artes, Valcárcel Medina es una obra extraña. No es el típico libro que haría un artista: dos de sus tres volúmenes abordan la historia entre el año 0 y el 2000, cada uno de los cuales ocupa una página; el tercer volumen contiene toda la parafernalia del trabajo del historiador: índice onomástico y toponímico y bibliografía. El resultado es aún más extraño si tenemos en cuenta que cada uno de estas páginas versa sobre un detalle mínimo, prácticamente una anécdota, con el que se pretende representar lo que ocurrió ese año en concreto. Este proceder nada tiene que ver con el descubrimiento del espacio en blanco de la hoja, de la relación entre la letra y su disposición en ese espacio que, tanto los poetas herederos de Noigandres como los poetas visuales en general, han desarrollado desde los años sesenta en España. $2000 d$. de $J$. C. es producto de un esforzado trabajo de investigación realizado por el propio Valcárcel Medina durante cinco años: de 1995, cuando ya el final del milenio se percibía en la cercana distancia, hasta 2001, cuando finalmente se publica la obra. No solo la investigación supuso un trabajo ímprobo y extenso, sino también su modo de producción y financiación: casi todas las páginas muestran en su parte inferior el nombre de quien ha financiado la investigación de ese año/página, revelando la economía que se esconde tras la investigación, tras el trabajo del artista. Todo encaja perfectamente, casi a modo de «perogrullo» (Benéitez: 773): dos mil páginas, dos mil años, una anécdota por cada página, casi todas con un patrocinador que ha pagado el coste, mil pesetas, de la investigación y una tirada de mil volúmenes.

La práctica que se hace del libro, cómo es usado y leído por el potencial lector, tampoco se puede considerar dentro de la norma que caracteriza a los libros de artista. En efecto, como también ha dicho el artista, «si el espectador quiere disfrutar del arte debe dar primer el callo» (en Díaz-Guardiola, 2015). La cita es una clara heredera del «Why not Sneeze Rrose Sélavy», homofonía por la que Marcel Duchamp declaraba que lo suyo no era nada fácil («Why isn’t Easy Rrose Sélavy»). La obra que lleva

\footnotetext{
${ }^{1}$ Esta investigación se ha desarrollado en el marco del proyecto de investigación «La Historia del Arte en España: devenir, discursos y propuestas» (Ministerio de Economía y Competitividad, HAR2012-32609).
} 
ese título, una jaula con cubitos de mármol, una espina de sepia sin raspar y un termómetro, era una clara alusión a la frialdad, frigidez más bien, de las receptoras del regalo. En el caso de Valcárcel, el erotismo, resquicio de lo libidinal, ha sido quirúrgicamente arrebatado. Este simplemente ha desaparecido, eliminado con la aplastante lógica de la estructura del libro. El peso, como en la jaula de cubos de mármol original — según dicen las malas lenguas, provocó una lesión en el hombro de su destinatario cuando la cogió- aún está presente: es el peso, en esta ocasión físico, de la historia. La obra no tiene nada de «una tirada de dados jamas abolirá el azar». La decepción del lector habitual de libros de artista está asegurada.

Pero si no cumple con la percepción habitual de un libro de artista en papel, ¿responde a la de un lector especialista, un lector interesado en lo que ocupa el libro, es decir, a un lector interesado en la historia en general? La pregunta no es en absoluto gratuita, pero para explicarla debemos recurrir a una experiencia personal. La primera vez que me topé con este libro lo encontré en una biblioteca de humanidades de una universidad madrileña. El encuentro fue verdaderamente inesperado: ocupaba la estantería de «libros de referencia» y era tan fundamental para la biblioteca que ni siquiera podía sacarse en préstamo. Era un libro que no podía faltar y que debía cumplir su función como libro de consulta básica: su referencialidad se debía, se entiende, a su supuesta capacidad para solucionar una duda ocasional que alguien pudiera tener sobre el transcurso de la historia. Pero en vez de eso, el lector ideal no encontraría lo que espera, sino tan solo una anécdota inútil si se quiere reconstruir la historia. Así, 711 niega corresponderse con la fecha de la entrada de los musulmanes en la Península que sitúa dos años antes. Se centra, sin embargo, en el nacimiento «del primer moro español». 1212 no aborda la Batalla de las Navas de Tolosa, sino el reclutamiento de un ejército de niños cuya inocencia aseguraría la victoria ante los musulmanes; los pocos que llegaron a su destino fueron hechos esclavos en Palestina. 1440 revela las consecuencias de la pérdida del centro del universo de la Tierra, según Nicolás de Cusa. De forma sorprendente, Jean Cocteau aparece mencionado por querer asegurarse un puesto como organizador de los misterios que nadie puede explicar. Si alguien quería saber los pormenores del descubrimiento de América iba a encontrar, sin embargo, cómo en las naves de Colón se percibió la declinación progresiva de la brújula. 1936 trata de una corrida de toros memorable a la que asistió Ortega.

El libro es elocuente en la ruptura de las funciones del discurso histórico. Imagino a nuestro lector universitario ideal que busca, no el arte, sino la historia. Es probable que nadie haya caído aún en que el libro no cumple con lo que, parece ser, la promesa que han depositado en él: ya han pasado más de ocho años desde aquél primer encuentro y sigue en el mismo sitio de la misma biblioteca. No puedo evitar perfilar un paralelismo con Douglas Crimp y su encuentro con el libro de fotografías de gasolineras de Ed Ruscha en la sección de «automóviles y carreteras» de la Biblioteca Pública de Nueva York (Crimp, 1993: 66-82). El encuentro también le maravilló ya que para él cumplía con la lógica del objeto artístico extraído del idílico espacio museal que asegura su completa inocencia, su absoluta asepsia. Crimp pensó, de hecho, que esa sección de automóviles y carreteras era su espacio ideal ya que cumplía a la perfección con lo que el libro mostraba: fotografías de las gasolineras que se 
encontraban en el Sunset Strip de Los Ángeles. Cómo había pasado a ser considerado una obra de arte, y no un objeto semejante a un calendario de gasolinera, era lo que parecía asombrar al crítico americano. El hallazgo era mucho más que una mera anécdota ya que suponía un ataque directo al espacio simbólico del arte, a una excepcionalidad que seguía vigente a pesar de Duchamp, de Warhol, de Ruscha mismo y de tantos otros que habían intentado borrar el espacio entre el arte y el resto de los objetos del mundo sin conseguirlo. Esa sección, pensó Crimp, era su sitio ideal ya que encontrarlo ahí implicaba interpretarlo fuera de los cánones del gusto artístico que, incluso en su etapa postmoderna, se emplean cuando se aborda una obra de arte. Encontrarlo en aquella sección destruía sin remisión la autonomía de la obra de arte, su aura como objeto cultual, y lo trasladaba a un espacio completamente diferente donde convivía con otros objetos sobre los que años de disciplina impiden que despleguemos la misma mirada aséptica: la fascinación y atracción que proveían las imágenes de Ruscha las hacían más puras, más somáticas en ese espacio que en aquel otro, el del arte, que en principio le era apropiado.

El libro de Valcárcel sigue más o menos la misma lógica: la institución a la que va destinada, el edificio del arte contemporáneo, es negado por la inclusión del libro en las coordenadas de otro aparato institucional, la disciplina de la Historia Universal. Es verdad que la seducción automovilística es de otro régimen completamente diferente, pero aun así el desplazamiento es de lo más interesante. Las convenciones históricas son ambiguas, se respetan y se incumplen simultáneamente, provocando una ruptura del relato histórico aceptado que se quiebra perdiéndose sin posibilidad de continuidad. El mismo año cero, que funciona a modo de prólogo, refleja un estado temporal idílico: un tiempo antes del tiempo, un imposible grado cero de la sucesión temporal, un antes del comienzo que deviene irreal, una farsa, una ficción.

Este año cero es que el que Valcárcel dedica a introducir la lógica del libro desvelando, al contrario de lo que hiciera Ruscha, la intención artística que se encuentra detrás del libro:

El recorrido, que se inicia de aquí a poco, está integrado por pequeños textos y está también plagado de autorreferencias a sí mismo... Pero aunque la gran mayoría de las dudas y curiosidades que el lector pueda tener sobre la naturaleza de esta obra o incluso sobre sus propósitos ha de quedar aclarada con su simple lectura, para los casos en que tal ventura no se dé, simplemente recordar que el arte no está para solucionar problemas, sino para crearlos [...]. En el fondo, tal vez pudiera pensarse que pocos libros menos históricos que $2000 d$. de J. C....; pocos que aspiren más a limpiarnos del peso del pasado y que se ocupen con más descaro del fluctuante posicionamiento ante la obra pendiente. Todo lo aquí contado ocurrió, pero idealmente, habría de flotar en una sensación de realidad sospechosa... (Valcárcel Medina 2001: 0).

Esa sospecha ante la realidad se produce constantemente a lo largo de toda la obra; los ejemplos del primer moro español, del secuestro de niños para organizar un ejército de inocentes, de las peripecias del de Cusa acompañadas por Cocteau o de la corrida de toros del 36 son una clara muestra de lo desnortado que uno puede acabar si lo que busca es el barniz enciclopédico. En muchos sentidos el resultado de la tarea del artista nos recuerda a la fábula de Bouvard y Pécuchet de Flaubert: siempre llevando al fracaso las estrictas indicaciones de la Enciclopedia en cualquier disciplina que uno intentara controlar. 
Una de las diferencias más notables de este libro reside en el modo particular con el que se se ha enfrentado a la historia. En efecto, como ha comentado ya Miguel A. Hernández-Navarro, desde la segunda mitad de los noventa la historia se ha convertido en uno de los campos más relevantes de la producción artística tanto en el extranjero como en nuestro país ${ }^{2}$. En el caso específico de España la Dictadura y la marca que imprimió a todo el pasado, cuyo último sello fue la Transición, han hecho que la historia reciente, especialmente la traumática, se haya convertido en el espacio predilecto para artistas que se han sentido atraídos por este ámbito. Con ello probablemente reconozcan que el pasado reciente en el Estado español es un verdadero problema que ha pregnado toda dimensión política, cultural y pública. El pasado de la Dictadura, con cadáveres aún en las cunetas, fosas comunes y familias completamente destrozadas, se erige como un trauma que requiere de una constante formulación. Este trauma revela sus profundas raíces con cada iniciativa privada por sacar los cadáveres de las cunetas, con cada intento de reivindicar la memoria de los desaparecidos, con cada cuerpo aún sin encontrar. Llamar historia a este proceso, en esta situación, no carece de cierta paradoja; el cierre que supone dicho concepto, como si estuviera remitido a un pasado finalmente clausurado, es negado traspasando el límite de lo pretérito para actualizarse constantemente en el ahora. De ahí que se pueda considerar más como memoria, con todo lo que dicho concepto conlleva de carga personal y no institucional, que de historia como un proceso plenamente cerrado, avalado por la institución y aceptado por el público.

La relevancia que en los últimos años está reflejando el pasado, la memoria y la historia es testigo de una actitud claramente postmoderna en la que el futuro ha dejado de contener toda ambición utópica para alojar la distopía del presente ${ }^{3}$. El pasado se recupera de todos los modos posibles: por el arte, como hemos visto, pero también como dilema legal, como ficción literaria, como monumento o antimonumento, e incluso como espectáculo, tal y como revela el creciente historicismo en la temática de muchas series de televisión. En muchas de estas, Nueva Arcadia de la narrativa audiovisual, se aborda el pasado desde una contemporaneidad que se convierte en la atalaya que permite evaluarlo. Con ello reproducen una concepción historicista basada en el progreso lineal y sucesivo a la que no se le escapa nada. Su lectura del pasado se basa en lo unívoco, en la certeza absoluta sobre un pasado que ha devenido pétreo e inamovible, so pena de poner patas arriba toda nuestra cotidianidad. La historia, parecen concluir, es aquello que se debe velar para que no cambie, para que no se transforme.

\footnotetext{
${ }^{2}$ Miguel A. Hernández-Navarro nos recuerda las exposiciones que explícitamente han abordado este tema en el contexto español: «El pasado en el presente y lo propio en lo ajeno» (Laboral, Gijón, 2008), «Imaginar-Historiar» (Ca2M, Móstoles, 2009), «Así se escribe la historia» (La casa Encendida, Madrid, 2008), «El instante de la Memoria. Narrar la historia» (ciclo de cine y talleres en el MNACRS, Madrid, 2010), «Ejercicios de memoria» (Centre d'Art La panera, Lleida, 2011). ${ }^{3}$ Como es conocido, esta es la tesis principal de Andreas Hyussen aunque también Fredric Jameson ha realizado una importante investigación sobre las utopías en el pasado. Es relevante considerar a ambos autores en este marco puesto que otrora fueron dos de los representantes más importantes de la historiografía postmoderna, que criticaban la concepción de la historia como pastiche del que se podían coger las referencias y modelos que se desease. Lógicamente, ello implicaba la aceptación de que ningún modelo narrativo era el dominante en la Postmodernidad y la aceptación del final de la historia al modo de Fukuyama. En cualquier caso, una vez abandonado el análisis de la propia pPostmodernidad, el retorno que estos autores revelan por la Historia y por los problemas de contarla, reflejo de una actitud contraria a lo moderno, se ha entendido de forma mucho menos apocalíptica. Vid. Hyussen (2002) y Jameson (2009).
} 
En el caso de los artistas españoles se ha dejado percibir una adopción de la Guerra Civil, la Dictadura y sus secuelas como ámbito predilecto donde enmarcar sus preocupaciones. Esta adopción certifica que la «dificultad de llegar a un acuerdo sobre la Guerra Civil española», como tituló un ensayo Jo Labanyi (2007), no es tan sólo una cuestión de medios de masas y de literatura blockbuster. El vídeo, por ejemplo, gracias a este tipo de preocupaciones abandonó el experimentalismo formal que le caracterizó durante los ochenta y parte de los noventa, para adoptar lenguajes que poseían un mayor grado de comunicabilidad. Fue el documental, con muchas variaciones sobre su modelo narrativo clásico (basado en la omnisciencia, voz en off que interpreta las imágenes, grabaciones ex profeso, conclusión y cierre de la trama), el que mayor desarrollo tuvo en este sentido. En manos de Marcelo Expósito se convirtió en uno de los dispositivos más relevantes para documentar partes del pasado que habían sido olvidados. Su La tierra de la madre (1994), en la que se atendía a los niños que tras la guerra fueron enviados a Rusia, suponía una revisión crítica que combinaba documentación, grabaciones fílmicas del pasado y la entrevista personal. María Ruido con sus dos partes de Plan Rosebud (2008) también se ciñó al ámbito de la memoria histórica, el turismo del horror y la cultura audiovisual generada en torno suyo.

También la fotografía ha sido otro recurso empleado, por ejemplo Francesc Torres y su trabajo documental sobre el trabajo en las fosas comunes revelan la materialidad de la memoria traumatizada. Pedro G. Romero y su Archivo FX es un proyecto que emplea diversos recursos, entre ellos imágenes de archivo, sobre el anticlericalismo que se acompañan de leyendas propias del vanguardismo iconoclasta. Francesc Abad, también con un trabajo de archivo, recupera la memoria del Camp de la Bota y de los fusilamientos que se realizaron allí durante la inmediata postguerra. Algunos, como Fernando Sánchez Castillo, han hecho del ímpetu historiográfico su ámbito de trabajo predilecto mediante la utilización del Azor, barco de recreo de Franco exhibido tras su desgüace, o de varias esculturas también de Franco a medio enterrar que confunden lo arqueológico con lo funerario.

Como se puede ver, la presencia del documentalismo en sus diferentes versiones (fotográfico, videográfico), de los recursos propios de la investigación histórica (los archivos, la documentación), o de las conmemoraciones públicas (los monumentos o antimonumentos) han sido los recursos más utilizados por los artistas españoles. Es por esta razón por lo que la construcción de realidad se entiende como uno de los objetivos más importantes de todos estos artistas: sus recursos construyen una realidad que ha sido ocultada y negada tendenciosamente. El uso de estos medios revela la necesidad de que el recuerdo que traen al presente no se confunda con ningún grado de ficcionalidad ${ }^{4}$. Muestran así la tragedia de la historia, su lado más terrible y mortífero (Hernández-Navarro, 2012: 87 y ss.). Es porque pretenden darle un vuelco a la historia por lo que sus recursos deben ser cercanos a la fidedigna

\footnotetext{
${ }^{4}$ Quizás se debería matizar que incluso la tradicional oposición que se hace entre real y ficción se encuentra en proceso de solapamiento en gran parte de la reflexión sobre la memoria en el siglo XXI. Plan Rosebud de M. Ruido, revela una cierta tendencia a pensar la ficción como un modo de producción de lo real. En este sentido, también Hito Steyerl ha realizado similar reflexión en vídeos como November (2004). En cualquier caso, se debe subrayar el hecho de que esta transgresión entre la narración de lo real y de lo ficticio implica una inversión en lo real que queda fortificado como producto también de la ficción.
} 
representación de la realidad: documento, archivo y monumento deben cuestionar el legado histórico que reciben, pero no deben sospechar sobre la realidad; si así fuera, permitirían que aquello que recuperan retorne tan sólo como simulacro. El retorno de lo real purgado del olvido es, en gran medida, el objetivo de estas prácticas.

El acercamiento de Valcárcel Medina en su 2000 d. de J. C. resulta interesante en estas coordenadas. Esto se debe no sólo por el hecho de que haya rechazado la idea de trauma sino por haberlo hecho precisamente de un modo que evidencia la construcción histórica - y debemos entender que la que él hace en su libro se proyecta a un campo más amplio. Es esa «sospecha sobre la realidad» aludida en el prólogo que debe dominar en toda la obra lo que la convierte en un trabajo absolutamente original. Ello no implica, ni mucho menos, un posicionamiento opuesto a los temas desvelados por la versión traumática de la historia, ni por los artistas que han seguido ese camino; que no siga esa senda no significa que la rechace, sino que propone otras preguntas diferentes, en esta ocasión a la historia en su conjunto. Su acercamiento divergente a la narrativa histórica, si bien no incide en lo traumático, revela el estrecho filo que recorre y que en ocasiones puede provocar la caída del principio de realidad. Las convenciones del relato histórico son respetadas hasta tal punto que prácticamente evidencian su artificio. No hay muchos en el ámbito en la historiografía que partan de la sospecha sobre el suelo que pisan, de encontrarse en un campo donde lo posible deviene verdadero a costa de nuestra voluntad de creer.

No es la primera vez que Valcárcel Medina ha abordado los modelos de narración. En 1972, con ocasión de los famosos Encuentros de Pamplona, realizó La Celosía, película basada en la novela de Robbe-Grillet, famoso escritor del nouveau roman francés. Decir que esta película se basa en la novela de Robbe-Grillet es ciertamente inadecuado, puesto que la película es el propio texto del autor francés. El texto del libro es lo que se proyecta en la propia pantalla mientras dos voces en off, una masculina y otra femenina alternándose, leen el texto proyectado en la pantalla. En algunos fragmentos de la película el texto aparece en francés original, siendo leído en español, o al revés. En otros momentos, el texto leído difiere del que es proyectado, no se lee en absoluto, o las voces leen el texto sin que este aparezca en pantalla. Hay otros fragmentos en los que se recurre a la superposición de las dos voces impidiendo la comprensión de lo que dicen. La estructura, en torno a textos y pantallas en blanco, voces y silencios, se rompe tan sólo con la proyección de algunos planos de viviendas — probablemente en respuesta a la formación de Valcárcel Medina como arquitecto- que parecen representar lo que las detalladísimas descripciones del libro dicen. Pero en realidad estos planos fracasan estrepitosamente en representar el texto: no tienen ninguna utilidad como visualización de lo descrito por el libro, ya que una atenta escucha demuestra que estos planos poco pueden aclarar lo que las palabras dicen. Es por esta razón por lo que reinciden en el hecho de que una perfecta descripción fracasa en representar aquello que describe: su estilo burocrático impide una traducción visual. Como ya ha detallado Amelia Gamoneda (2016: 2-3), el detallismo descriptivo de la novela se justifica por un narrador de mirada vigilante y obsesiva al cual se le ha sustraído la acertada percepción de la realidad. Frente a este déficit interpretativo, el narrador, convertido en descriptor, tan sólo puede detallar quirúrgicamente su entorno 
sin ser capaz de interpretarlo. Un efecto semejante se produce en la película de Valcárcel Medina. El distanciamiento que se destila de las voces leyendo rápidamente y con un tono racional, casi notarial, tan sólo se rompe con el efecto de eco de la voz femenina que ni siquiera aporta dramatización a la trama que, como es conocido, se basa en la celotipia.

El resultado de la película parece incidir en la estratificación de la traducción: el libro se traduce en la película; la película proyecta el libro que traduce en actos del habla; los diagramas traducen lugares; las voces leen un texto que no se ve en pantalla. A pesar de estos diferentes estratos, la traducción se torna imposible: ni la lectura vuelve comprensible el texto, ni las voces en off ilustran la imagen, ni los planos aclaran las descripciones. La traducción no permite que el mensaje se entienda mejor sino todo lo contrario: queda encerrado en la impenetrable cápsula que lo rodea.

La Celosía supone un verdadero reto a los modos de percepción audiovisual más habituales. La película se ve pero al mismo tiempo se oye, se lee negando la función de espectador como voyeur idealizado en favor de un lector que lee y escucha en una estancia pública - la sala de cine- La narrativa que esperaríamos encontrar en una película tradicional está completamente ausente. Ni siquiera el silencio que debe dominar en estas salas de cine está asegurado con una película como esta: no hay nada en la película que nos impida leer en voz alta el texto sumándonos a la cacofonía de voces, ni que, llegado el momento, respondamos a las voces o incluso que gritemos a la pantalla. El modo de percepción de La celosía no está inscrito en la película y muy bien podría ser otro del que se acostumbra en la sala de cine. Es más, la proyección de la película ha despertado en ocasiones las más extrañas reacciones del público: como describen Carolina Pérez Parra y Ángel Pérez Villén, el público de la Filmoteca de Madrid llegó a pedir la devolución del coste de la entrada con motivo de la proyección de esta película (Pérez Parra, 2000: 228). Es por esta razón por lo que resulta difícil no relacionar esta misma película con las de la Internacional Letrista y Situacionista. El interés del Letrismo en agredir al cine por medios propios — rasgando, cortando, pintando encima del celuloide — o por la directa agresión al espectador parece encontrar eco en la película de Valcárcel. Desconocemos, sin embargo, si esta era una intención buscada por el propio Valcárcel o, incluso, si conoció las películas de la Internacional Letrista o Situacionista.

Valcárcel Medina también ha trabajado con las paradojas de la documentación como prueba de lo real. En 2013, el colectivo «If I can't dance I don't wanna be a part of your revolution» publicaba el libro 18 fotografías y 18 historias donde abordaba las performances realizadas por Valcárcel Medina a lo largo de toda su trayectoria pero que, por cualquier razón, no habían sido documentadas fotográficamente. De este modo, el libro se organizaba en torno a dieciocho performances del pasado sobre las que glosan algunos de los autores participantes en la edición. Más interesante para la perspectiva documental que nos ocupa ahora, es que esas obras fueron reescenificadas por el propio Valcárcel Medina y fotografiadas para ser incluidas como parte del trabajo documental de una obra efímera que se había realizado, en algunos casos, hacía más de cuarenta años.

Este curioso proceder - realizar la documentación de una obra cuarenta años después de su realización original - tiene algo de performativo en sí mismo. Como ha explicado hace ya tiempo 
Philip Auslander (2006), la fotografía, es decir, la documentación de una obra performativa, tiene una importante labor pero no como mera documentación del hecho, sino más importante aún: la documentación construye la propia obra, performa la obra de performance o, como titula Auslander, consiste en la «performatividad de la documentación de performance». De ahí que sin documentación no haya obra performativa.

Este nexo entre el documento y lo real es, como sabemos, uno de los más relevantes fundamentos de la investigación histórica y en su vínculo, quizás demasiado literal, nos puede llevar a confundir la documentación original con la repetición ficcionada, como en el caso de Valcárcel Medina. Otro caso paradigmático nos lo plantea el propio Auslander, y consiste en las fotografías Salto al vacío de Yves Klein (1960), una interesante fotografía en la que el artista aparecía saltando de una altísima tapia asegurándose su inmediata entrada en urgencias. Como es de sobra conocido, la fotografía estaba trucada y los amigos del artista, lona en mano para amortiguar la caída, fueron eliminados de la fotografía que finalmente se trucó con otra toma en la que, en vez de los acólitos, aparecía un ciclista en la lejanía. A pesar de ello, Auslander asegura que el hecho, la obra performativa, está producida por la propia fotografía usurpando así el contenido ficticio, fantasmático y simulacral de muchas obras del mismo artista ( $\sin$ ir más lejos, se dice que lanzó uno de sus manifiestos con una avioneta cuando las fotografías claramente le muestran en tierra firme haciendo - es decir, simulando- el acto). La construcción del mito del artista, y no solo la mera performatividad, era una de las inquietudes más relevantes de Klein.

La fotografía, cuando se aplica a la performance, revela la necesidad que aún tenemos de contar con el documento acreditativo como eje esencial de la burocracia histórica. Otros autores, como Rebecca Schneider (2010), han abogado por un archivo corporal que rechace el logos en favor de una memoria somática que invierta la lógica del archivo. En el caso que nos encontramos de Valcárcel Medina y de sus 18 fotografías, no deja de resultar interesante el palimpsesto que genera: la documentación que funda el hecho, es decir lo real, ha sido generada a posteriori, repitiendo el hecho primigenio mucho tiempo después. Es tan sólo así como ambos, hecho original y documentación, son introducidos en el flujo de la historia del arte presente. Tragedia y farsa fundidos en uno gracias a la documentación histórica. Paradójicamente la primera de estas fotografías documentaba en retrospectiva una acción de 1969 realizada en Madrid y en Murcia. Campaña consistía en una acción en la que Valcárcel Medina distribuía en la calle unas octavillas a los viandantes, como si se tratara de los típicos mensajes publicitarios de marketing directo. En ellas se podía leer: «No olvide olvidarlo una vez leído». Narración, documento, memoria, olvido, producción de historia, parecen ser temas recurrentes en la obra de Valcárcel Medina prácticamente desde sus orígenes.

Pero si $2000 d$. de J. C. se basa en todos estos procesos de narración, producción de la memoria y al mismo tiempo del olvido, el resorte que activa es muy particular. Nuestro lector ideal, aquél que imaginábamos al principio de este estas páginas cogiendo la publicación de la estantería de «libros de referencia», qué modelo historiográfico encontrará en sus páginas. Beatriz Herráez, en un breve ensayo sobre esta obra, identificaba como posible paralelo de la obra de Valcárcel Medina a la microhistoria 
de Carlo Ginzburg. Su carácter aforístico y su forma sostienen la comparación. En palabras de Herráez, la microhistoria se caracterizaría por «Un modo de proceder que se sostiene en los pequeños detalles, en el hecho de prestar atención a lo anecdótico y lo subsidiario, a los síntomas y a los indicios que, sin embargo y a pesar de su carácter secundario, pueden revelar cuestiones principales de cada narración» (Herráez, 2014: 127).

A pesar de la semejanza en la forma ambas empresas son, sin embargo, muy diferentes. Como es conocido, la microhistoria de Ginzburg surge en un momento en el que se percibe un fuerte interés por introducir los relatos no dominantes en el discurso histórico. Lo cotidiano y la individualidad subcultural se convierten entonces en ejes esenciales de donde poder contrastar cómo la gran historia se filtraba en la vida cotidiana de la gente común. Frente a los que aseguraban que la cultura oficial determinaba los modos de vida y de percepción de la realidad de las clases dominadas, Ginzburg pensaba que se podían encontrar modos de resistencia que no habían tenido cabida en los archivos, asimismo herramientas de control social. Su microhistoria, por tanto, es un modo de entender el engranaje entre culturas dominantes y subculturas.

Resulta ilustrativa la comparación entre la microhistoria de Ginzburg y la labor del historiador inglés Edward P. Thompson. Su La formación histórica de la clase obrera en Inglaterra (1963) supone uno de los intentos más evidentes por elaborar un análisis de los grupos sociales atendiendo, en especial, a la dimensión cotidiana (Muñoz, 2009: 10-12). Es exactamente en la perspectiva social que adoptan Thompson y Ginzburg en donde se pueden encontrar las diferencias: el primero está interesado en la idea de colectividad, corporeizada en la forma de clase, mientras la microhistoria revela un carácter menos expansivo socialmente, más individualizado. Uno de los mayores éxitos bibliográficos de Ginzburg, El queso y los gusanos, se concentra en un molinero, Doménico Scandela «Menochio», juzgado por la Inquisición y muerto en la hoguera. La documentación sobre el juicio revela una extraña cualidad del sujeto en cuestión: en primer lugar, era letrado y tenía una importante cultura literaria que le habían dotado de una posición ideológica claramente contraria al statu quo, lo que que le llevó a su trágico final. En segundo lugar, este ejemplo revela la interacción específica que en el siglo XVI existía entre las clases dominantes y las subalternas, verdadero objeto de estudio de Ginzburg. Así, la diferencia entre Thompson y Ginzburg es más bien de procedimiento: donde para Thompson la clase es punto de partida para que sea reconstruida, para Ginzburg es el individuo, su casuística particular, lo que da cuerpo a las luchas culturales y a las resistencias en un caso concreto. El objetivo es el mismo —el análisis de la cultura popular - pero el procedimiento es dispar: «Menocchio», al fin y al cabo, es un sujeto al que se llega por su presencia en un documento archivado sobre su causa, tan sólo un miembro de una clase. Se destila cierto positivismo metodológico que, como el mismo Ginzburg indica en su introducción, es exactamente lo que aterra a Thompson.

La microhistoria, en definitiva, poco tiene ver con el estilo, menos aún con lo anecdótico. Más bien está vinculado con cómo todo un estrato social puede estar representado en el microcosmos de un sujeto individualizado. En este sentido, el concepto micro se entiende en el mismo sentido que tiene en «microcosmos», término empleado por el propio Ginzburg (1981: 9). En cualquier caso, para lo 
que nos interesa en relación a Valcárcel Medina, ambas historiografías tienen un sujeto histórico: la clase obrera y el pobre molinero sobre los que se versa en ambos modelos historiográficos. Este proceder dista mucho de la cantidad de sujetos, anécdotas, historias, que pululan por el libro de Valcárcel Medina, que aparecen para rápidamente desaparecer sin haber ningún nexo entre ellos ni forma de unificarlos de modo alguno.

Ginzburg advierte de los peligros de su acercamiento, lo cual resulta productivo si se aplica al estudio de la obra de Valcárcel Medina: «Existe ciertamente el riesgo de caer en la anécdota, en la vilipendiada histoire événementielle (que no es sólo, ni necesariamente, historia política)» (Ginzburg 1981: 9). Como es conocido, la historia «evenemencial», centrada en el acontecimiento como eje central de la investigación, fue un modelo historiográfico erudito característico de la Francia del XIX. Superada por la Escuela de los Annales ya a principios del XX, se considera en la actualidad un modelo pretérito y sin una correspondencia con los intereses dominantes en la historiografía contemporánea. El libro de Valcárcel Medina no se puede entender como historia evenemencial en sentido estricto: sus continuas referencias a otras secciones del libro, sus valoraciones particulares que introducen al autor como parte esencial en la valoración del hecho histórico, la parafernalia de la historiadoria en forma de bibliografía, índice onomástico y toponímico, evitan toda aproximación centrada en el positivismo del acontecimiento. Del mismo modo, su alusión al ambiente de sospecha de la realidad que rodea a toda la obra también hace que incluso los acontecimientos que se exponen rechacen encarnar plenamente lo real. Aún así, la concentración en el evento determina la estructura del libro que básicamente se puede describir como un cúmulo de acontecimientos (raros y escasamente advertidos) que han acaecido a lo largo de la historia. Claramente, Valcárcel Medina consigue este efecto con una narrativa que evidencia el límite entre el discurso histórico y el de ficción, y resulta extremadamente sugerente pensar que lo consigue empleando un modo de escritura pretérito, que no tiene cabida en la actualidad pero que recupera modos de historización del pasado.

Dos modelos narrativos extemporáneos, además del evenemencial, parecen converger en 2000 d. de J. C. En primer lugar, el «anuario», esa forma de contar la historia que consistía en el año al que le seguía un breve comentario sobre el acontecimiento más destacado ocurrido durante dicha fecha. Por otro lado, «la crónica», la narración ordenada de los acontecimientos que han ocurrido en un espacio determinado (White, 1992a: 16-17). Ninguna de las dos están plenamente representadas en 2000 d. de J. C.: los anuarios originales son más bien parcos, comentando tan sólo un hecho sin prácticamente narración de ningún tipo; incluso dejan de listar algunos años evidenciando que nada digno de mención ocurrió entonces. Las crónicas suelen revelar a un escritor que ha participado en el hecho que narra, que es testigo, y además se suelen concentrar en un lugar específico sobre el que se cuenta la historia. Existen muchas diferencias entre estos dos modelos historiográficos y el libro de Valcárcel, que posee un carácter único; pero también comparten muchas semejanzas que resultan ilustrativas a la hora de analizarlo. La estructura año por año, una narración directa sin respetar la distancia con el hecho narrado, la representación de lo anecdótico, la ausencia de un sujeto histórico 
y, por tanto, la carencia de un nudo dramático y de un final asociable a ningún thelos más allá del cero como origen y el 2000 como final.

Hayden White (1992a: 15-16), historiógrafo esencial en el análisis formal de la escritura histórica, entiende que tanto el anuario como las crónicas son modos primitivos de relatos históricos, de hecho los más primitivos de la narración histórica. Sin embargo, dicho primitivismo no implica que sean pensados como formas fallidas e imperfectas de construcción histórica. Para este autor, que ha encontrado su especial campo de investigación en las diferencias entre la narración de ficción y la historiográfica, ambas formas representaban en su momento el mejor modelo del que se disponía para contar el paso del tiempo. Si ahora nos parecen deficitarios, incapaces de representar de forma adecuada el pasado, es porque existen otros modelos de escritura en los que hemos depositado nuestra credibilidad. Pero nadie puede asegurar que estos nuevos modos historiográficos sean a su vez superados por otros que evidencien la artificialidad de los que ahora nos parecen idóneos, desbancándolos por su inutilidad como discurso. La sucesión de los modelos narrativos no explica, viene a decirnos White, la progresión hacia el modelo dominante y perfeccionado que manejamos en la actualidad, sino que es reflejo de las diferentes funciones que se depositan en la escritura de la historia y en sus diferentes recursos narrativos. Por tanto, el modo de narración no es tan sólo una formalidad sino que también conlleva un alto grado de contenido — de ahí el título de su famoso libro, «el contenido de la forma»-. Por poner un ejemplo claro, cuando en las narrativas de los anuarios se omiten varios años no sólo se está indicando lo escasamente relevante de lo ocurrido, también se está representando el paso del tiempo de un modo precario pero, al fin y al cabo, válido.

$2000 \mathrm{~d}$. de J. C., con su narrativa a medio camino entre lo real y la ficción, entre el anuario y la crónica, entre los modelos pretéritos de narrativa histórica y la sospecha de su veracidad, establece una extraña distancia con el lector. Un distanciamiento producto de la forma narrativa, cuyo resultado es la inaprensibilidad de lo histórico a pesar de que todos los recursos de la escritura histórica se encuentren allí (algunos, es verdad, ya caducados). Nuestro lector universitario ideal, aquél que agarraba uno de los volúmenes para ver qué era lo más importante que acaeció en tal o cual año, no debe esperar mucho para ver que su objetivo nunca se verá cumplido en $2000 \mathrm{~d}$. de J. C.: no tendrá acceso a la historia que le promete el título, a lo mejor tan solo a su trastero.

Pero además de ese espacio de duda sobre lo histórico que Valcárcel Medina avanza ya en ese imposible año cero que prologa el libro, hay otro aspecto que va a conducir las últimas páginas de este escrito. Su «capacidad para limpiarnos del peso del pasado» debe ser considerado como el leitmotiv, a lo mejor político, de su libro. Quizás se haya pasado por alto en los pocos textos que han analizado esta obra una coincidencia histórica que puede ilustrar la naturaleza esquiva de este trabajo. Los años que el artista dedicó en abordar este trabajo, de 1995 a 2000, coincidieron con un momento en el que la reflexión histórica, especialmente en su implicaciones pedagógicas, se convirtió en un asunto central del debate político, llegando incluso a saltar a la palestra de la esfera pública. Como han recogido Luisa Elena Delgado y, en su momento, Pedro Ruiz Torres, en 1996, el debate se inició con un discurso de la ministra de Cultura y Educación del momento, Esperanza Aguirre, en la Real Academia de la 
Historia en el que proponía una revisión del modo en el que se enseñaba la historia en la educación obligatoria. Verdaderamente se trataba de una crítica al anterior gobierno del PSOE que, en efecto, había reducido la enseñanza de esta asignatura hasta el mínimo, empobreciendo también los recursos con los que se ejercía la pedagogía (un proceso que desde entonces ha sido la norma en cualquier gobierno). En aquella ocasión y según la autora del discurso, la situación tenía tintes dramáticos y justificaba una renovación de los modelos de enseñanza de la historia que suplirían el empobrecimiento histórico del alumnado que podía pasar por el bachillerato sin escuchar una palabra de Julio César o de Felipe II.

Fue de este modo cómo comenzó lo que se dio en llamar «Plan de las Humanidades», verdaderamente una reforma educativa que, en el ámbito histórico, se centraría en varios aspectos esenciales: la cronología, entendida por la autora como «esqueleto de la historia», la objetividad y la relevancia de España en el proceso histórico internacional. Muy pocos pueden tener dudas de que la historia tiene un principal objetivo disciplinar, como es la construcción de la identidad nacional. En este caso en concreto, ni si quiera se matizaba: España era una entidad transhistórica que no estaba cruzada por ningún tipo de dilema ni identidad que socavara su autonomía. La objetividad de la cronología, del «esqueleto» de la historia, venía a certificar lo científico del aserto que se debía imponer por su propia lógica aplastante. Al parecer, la ministra no contaba en absoluto con la tormenta que despertó su propuesta, especialmente entre los partidos nacionalistas de los que ese gobierno además se tenía que valer para poder sacar sus propuestas adelante. Estos sí entendían claramente que la estrategia tenía mucho de conciencia nacional, como ha advertido Javier Tussel (2004: 99-106).

La bronca tuvo especial proyección en los medios, con centenares de artículos en todas las direcciones posibles. Los estudiosos especialistas en la materia fueron muy poco tenidos en cuenta, lo que remite el asunto al escenario mediático y a la trifulca parlamentaria. Nunca antes, según parece, la historia fue tan relevante en el debate político ni estuvo tan de actualidad. La ministra ni contaba con los votos ni hizo lo necesario para obtenerlos, fracasando finalmente en su propuesta. No se realizó ningún estudio ni ningún informe que pusiera la cuestión en contexto, ni se realizaron comparativas con otros países del entorno. Esto revela que la propuesta no abordaba un verdadero problema en la enseñanza sino que tan solo se proponía como una forma de intentar imponer una visión particular que se hacía pasar por estructural, objetiva y común. Lógicamente perdió la votación y el debate se derivó hacia una comisión que finalmente hizo una serie de propuestas tan vagas como para que, en ese ambiente, fueran aceptadas ya a finales de 1997.

Es difícil saber cómo reaccionaba Valcárcel Medina ante esta situación mientras investigaba para su libro. Sin embargo, resulta interesante ver cómo la coincidencia temporal entre ambos hechos establecen un diálogo muy ilustrativo. Como se puede ver perfectamente, la estrategia de la ministra Aguirre perseguía la utilización de la pedagogía sobre la historia como forma de producir un consenso forzado sobre la realidad histórica de España. Su preocupación no era la historia; si así hubiera sido habría encargado estudios, quizás un congreso internacional que abordara el asunto, habría consultado a reputados historiadores e incluso a pedagogos que le clarificaran las dificultades concretas de la 
enseñanza de la historia. En cualquier caso no hubiera empleado una institución zombi como es la Academia de Historia para leer el discurso con el que empezó toda la polémica. La verdadera función de la Academia tan sólo se revelaría en 2011 con la edición del conocido Diccionario Biográfico Español en el que el dictador dejaba de serlo y con él, la Dictadura. La preocupación de la ministra residía más bien en la necesidad de que la historia se acoplara a lo que desde su peculiar particularismo pensaba que era la realidad de España. Es difícil imaginarse un mejor ejemplo que revele la función que aún sigue teniendo el discurso histórico. Su capacidad de producir lo real es todavía algo asumido plenamente en el presente. La historia, en la mente de la ministra, es exactamente la herramienta que permitirá cerrar la sutura que impide la homogeneidad de la nación española, su cohesión, su vertebración — término éste tan óseo como el de «esqueleto» que vinculaba a la cronología-.

Luisa Elena Delgado (2014: 73-74) ha utilizado el término psicoanalítico de la fantasía para describir cómo se producen los procesos de identificación social. Empleando las influencias de lo que llama la izquierda lacaniana (el conjunto de pensadores entre los que están Slavoj Žižek, Ernesto Laclau y Yanis Stravrakakis) entiende la fantasía como la herramienta que permite dotar de coherencia a lo real. Sin embargo, dentro de la lógica psicoanalítica, la fantasía tiene un doble sentido: por un lado cohesiona la percepción de la realidad, por otro nos aleja de la realidad. Esto se debe a que el acceso completo a lo real implicaría la desaparición de la fantasía que, paradójicamente, es lo que permite el acceso a lo real. La fantasía debe desvanecerse para acceder a lo real, pero lo real es inaccesible sin la mediación de la relación fantasmática.

2000 d. de J. C. parecería ocupar un espacio extraño dentro del este esquema psicoanalítico. Los recursos de la producción del discurso histórico se encuentran allí: la cronología, el desarrollo temporal, la bibliografía, el autor... Pero de una forma tan obscena, tan evidentemente extemporánea y artificial, que deja ver su cualidad construida, el modo de producción sobre el que se construye el relato. Esta inserción del modo de producción en el producto es especialmente evidente en la inclusión de las personas que han subvencionado la investigación de cada uno de los años, donantes que han pagado las mil pesetas que parece ser el coste de investigar cada año. De algún modo, Valcárcel Medina construye la fantasía sin esconder su artilugio, haciéndola evidente al mismo tiempo. En un libro elocuentemente titulado Historia y psicoanálisis, Michel de Certeau encontraba semejanzas entre el discurso histórico y el mediático en su ocultación de los modos de producción. Ambos ocultaban las instituciones sobre las que se erigían, las intenciones que perseguían, las relaciones laborales de las que eran fruto, los intereses, las políticas, las relaciones de poder y las estructuras sobre las que ambas se habían erigido (Certeau 2003: 5). El consejo del historiador parecía sencillo: mostrar el modo de producción para no esconder el andamiaje sobre el que se sostiene. En esas circunstancias la identificación, la subjetividad que se creaba a partir del discurso, es decir, la identidad nacional, era, cuando menos, puesta en suspenso.

Nuestro lector ideal, aquél que buscaba informarse sobre la historia universal en los pasillos de la biblioteca, quedará desdibujado. No encontrará lo que busca, tan sólo un cúmulo de historias y anécdotas que no darán cuenta de la historia que se desea atesorar, de lo real que se esconde, en 
apariencia, tras ella. Lo fantástico, la sospecha sobre lo real, ciertamente sobrevuela la obra; el peso de la historia, al fin, se nos ha sustraído.

\section{Bibliografía}

Auslander, P. (2006): «The Performativity of Performance Documentation», Performance Art Journal, 84, pp. 1-10.

BENÉITEZ, R. (2011): «La experiencia estética de Isidoro Valcárcel Medina: discurso vital y producción artística en el último cuarto del siglo XX», Artigrama, 26, pp. 769-779.

BuleOGA, Z.-B. (2013): 18 fotografías, 18 performances. Ámsterdam, If I can’t dance I don't want to be a part of your revolution.

Certeau, M. DE (2003): Historia y psicoanálisis. Trad. Alfonso Mendiola y Marcela Cinta. México, Universidad Iberoamericana.

CRIMP, D. (1993): «The Museum's Old, The Library's New Subject», en On the Museum's Ruins. Cambridge, MIT Press, $4^{\mathrm{a}}$ ed., 2000, pp. 66-82.

DíAZ-GuARDiOla, J. (2015): «Isidoro Valcárcel Medina: "Si el espectador desea disfrutar del arte debe dar primero el callo», ABC Cultural (24-1-2015); en http://www.abc.es/cultura/20150127/abcientrevista-isidoro-valcarcel-medina-201501261142.html (última consulta 22 de marzo de 2016).

Elena Delgado, L. (2014): La nación singular. Fantasías de la normalidad española (1996-2011). Madrid, Alianza.

FREDRIC, J. (2009): Arqueologías del futuro. El deseo llamado utopía y otras aproximaciones de ciencia ficción. Trad. Cristina Peña Aldao, Madrid, Akal.

GAMONEDA LANZA, A. (2016): «La descripción especular. Lectura neurocognitiva de La Jalousie de Robbe-Grillet», Tropelías. Revista de Teoría de la Literatura y Literatura Comparada, 25, pp. $1-16$.

GinZBurG, C. (1981): El queso y los gusanos. Trad. Francisco Martín. Barcelona, Muchnik, 4ª ed., 1997.

GonZÁlez, C. (2008): «Así se escribe la historia», en AA. VV., Inéditos 2008. Madrid, La Casa Encendida, pp. 17-47.

HERnÁNDEZ-NAVARRO, M. Á. (2012): Materializar la historia. El artista como historiador (Benjaminiano). Murcia, Micromegas.

Herráez, B. (2014): «2000 d. de J. C. de Valcárcel Medina», Concreta, 3, pp. 126-129.

Huyssen, A. (2002): En busca del futuro perdido. Trad. Silvia Fehrman. México, Fondo de Cultura Económica.

LABANYI, J. (2007): «Memory and Modernity in Democratic Spain: the Difficulty of Coming to Terms with the Spanish Civil War», Poetics Today, 28/1, pp. 89-116.

MuÑoz, B. (2009) «La escuela de Birmingham: sintaxis de la cotidianeidad como producción social de la conciencia», I/C - Revista Científica de Información y Comunicación, 6, pp. 21-68. 
PÉREZ PARRA, C. (2000): «Arte contra el sistema. Isidoro Valcárcel Medina», Imafronte, 15, pp. 225 236.

RUIZ TORRES, P. (1998): «La historia en el debate político sobre la enseñanza de las humanidades», Ayer, 30, pp. 63-100.

SCHNEIDER, R. (2010): «Los restos de la performance (reelaboración)», en I. NAVERÁN, ed., Hacer Historia. Reflexiones desde la práctica de la danza. Barcelona, Mercat dels Flors, pp. 171-198.

Tussel, J. (2004): El aznarato: el gobierno del Partido Popular: 1996-2003. Madrid, Aguilar.

VAlCÁrcel MedinA, I. (2001): 2000 d. de J. C. Madrid, Entreascuas Editores (3 vóls.).

WhITE, H. (1992a): Metahistoria. La imaginación histórica en la Europa del siglo XIX. Trad. Estela Mastrangelo. México, Fondo de Cultura Económica, 2a ed., 2001.

(1992b): «El valor de la narrativa en la representación de la realidad», en El contenido de la forma. Trad. Jorge Vigil Rubio. Buenos Aires, Paidós, pp. 18-39. 